\title{
Evolutionary geomorphology: thresholds and nonlinearity in landform response to environmental change
}

\author{
J. D. Phillips \\ Tobacco Road Research Team, Department of Geography, University of Kentucky, Lexington, KY 40506-0027, USA
}

Received: 10 January 2006 - Published in Hydrol. Earth Syst. Sci. Discuss.: 4 April 2006

Revised: 7 July 2006 - Accepted: 5 October 2006 - Published: 9 October 2006

\begin{abstract}
Geomorphic systems are typically nonlinear, owing largely to their threshold-dominated nature (but due to other factors as well). Nonlinear geomorphic systems may exhibit complex behaviors not possible in linear systems, including dynamical instability and deterministic chaos. The latter are common in geomorphology, indicating that small, short-lived changes may produce disproportionately large and long-lived results; that evidence of geomorphic change may not reflect proportionally large external forcings; and that geomorphic systems may have multiple potential response trajectories or modes of adjustment to change. Instability and chaos do not preclude predictability, but do modify the context of predictability. The presence of chaotic dynamics inhibits or excludes some forms of predicability and prediction techniques, but does not preclude, and enables, others. These dynamics also make spatial and historical contingency inevitable: geography and history matter. Geomorphic systems are thus governed by a combination of "global" laws, generalizations and relationships that are largely (if not wholly) independent of time and place, and "local" place and/or time-contingent factors. The more factors incorporated in the representation of any geomorphic system, the more singular the results or description are. Generalization is enhanced by reducing rather than increasing the number of factors considered. Prediction of geomorphic responses calls for a recursive approach whereby global laws and local contingencies are used to constrain each other. More specifically a methodology whereby local details are embedded within simple but more highly general phenomenological models is advocated. As landscapes and landforms change in response to climate and other forcings, it cannot be assumed that geomorphic systems progress along any particular pathway. Geomorphic systems are evolutionary in the sense of being path dependent, and historically and geographically contingent.
\end{abstract}

Correspondence to: J. D. Phillips

(jdp@uky.edu)
Assessing and predicting geomorphic responses obliges us to engage these contingencies, which often arise from nonlinear complexities. We are obliged, then, to practice evolutionary geomorphology: an approach to the study of surface processes and landforms which recognizes multiple possible historical pathways rather than an inexorable progression toward some equilbribrium state or along a cyclic pattern.

\section{Introduction}

Geomorphologists have long made reference to landform and landscape evolution, usually using the latter word as a general term referring to change over time. Traditional chronological models of landscape evolution such as those of Davis, Penck, and King postulate a deterministic cycle or progression of forms. Process-based "equilibrium" models also postulate a specific developmental pathway, towards some final steady-state. To the extent these models apply, they simplify efforts to predict the response of earth surface processes and landforms to climate and other environmental changes. In equilibrium-based theory, a given set of boundary conditions produces a given outcome, indicating that we should be able to work out a one-to-one correspondence between changes in boundary conditions and geomorphic reponse. In cyclical models, exogenous changes can be treated as interruptions, accelerations, or decelerations of the prescribed cycles.

Though existing models of landscape evolution and geomorphic response to disturbance are all applicable in some situations, none provides a general framework applicable to all (or even a majority of) geomorphic systems. Further, geomorphic change over time is often characterized by pathways more complex than progression toward some endstate, be the latter a planation surface, equilbrium form, mature zonal soil, or other hypothesized destination. Accordingly, several geomorphologists have espoused an explicitly evolutionary approach that distinguishes between complex,

Published by Copernicus GmbH on behalf of the European Geosciences Union. 
nonlinear, historically contingent, path-dependent evolution and classically deterministic development over time. This paper explores the links between evolutionary geomorphology, thresholds, and nonlinear dynamics, in the context of predicting effects of environmental change on geomorphic systems. Special attention is given to implications regarding geographical and historical contingency.

\subsection{Evolutionary geomorphology}

Instead of seeking universal theories (be they based on equilibrium notions, cycles, or otherwise), Ollier (1979) suggested, it might be more useful to see how landscapes actually evolve. Ollier's evolutionary geomorphology emphasizes dates, ages, and history, and stresses the consistent internal (to the landscape or system under study) evidence rather than a priori theoretical notions. Ollier (1979) does not advocate anecdotal, atheoretical approaches, but rather adapting or devising conceptual frameworks to fit the evidence rather than imposing conceptual frameworks at the beginning. The evolutionary geomorphology of Ollier can be interpreted as working out the pathway or trajectory of change in a multidimensional space encompassing multiple possibilities.

Thornes' (1983) vision of evolutionary geomorphology is also concerned with the long-term behavior of landforms. Thornes (1983) laid out a blueprint for evolutionary geomorphology based on complex dynamical systems. Defining an area dominated by a particular landform or process as a domain, process geomorphology is chiefly concerned with behavior determining the character and configuration of the domains. Evolutionary geomorphology, by contrast, is concerned with "the initiation and development of the structure giving rise to the domains" (Thornes, 1983:227). Structure here refers to the structural relationships among processes, geological controls, climate, relief, and other factors rather than geological structure per se, and evolutionary geomorphology is portrayed as being more analytical than chronological approaches which essentially describe particular historical pathways. Thornes explicitly (rather than implicitly as in Ollier's case) advocated a concern with defining geomorphic system trajectories through a multidimensional phase or state space defined by the key variables or components of the system.

In soil geomorphology, Johnson and colleagues (Johnson and Watson-Stegner, 1987; Johnson et al., 1990) challenged the view of pedogenesis as an inexorable (though perhaps occasionally interrupted) pathway of increasing pedological development toward a steady-state climax soil. The evolutionary model of pedogenesis (Johnson and Watson-Stegner, 1987) allows for the possibilities of both progressive and regressive pedogenesis, and for complex changes in the state of the soil landscape. This model was explicitly linked to dynamical systems by Johnson et al. (1990), and to complex nonlinear dynamics by Phillips (1993).
Huggett $(1995,1997)$ is concerned with geoecosystems, including geomorphic systems, more generally. He contrasted an evolutionary viewpoint with a "developmental" view characterized by progress along a predetermined path, whether a Davisian cycle or progress toward a single steadystate equilibrium. Huggett's evolutionary approach emphasizes inconstancy, based on the unlikelihood of sufficient time for full developmental sequences to occur, the likelihood of nonlinearity and complexity, and dependence on initial conditions. An evolutionary view thus recognizes that at any instant earth surface "systems are unique and constantly changing, and are greatly influenced by historical events (owing to the relevance of initial conditions)" (Huggett, 1997:315). The historical path of an earth surface system is interpreted in an evolutionary context as changes in the state of the system rather than as progression (or retrogression) along a particular developmental pathway (Huggett, 1995:268).

The notions of evolutionary geomorphology outlined above are consistent in several regards. All are concerned with change over time in landforms and landscapes, emphasizing historical and geological time scales. All recognize multiple possible historical pathways for such changes, rather than an inevitable progression toward some final equilibrium state or along a cyclic pattern. The conceptions of evolutionary geomorphology explicitly acknowledge historical contingency, whether in the form of inheritance, pathdependence, or dependence on initial conditions.

Applications of nonlinear and complex systems analysis in the geosciences has often been (accurately) characterized as the importation of ideas from systems theory, mathematics, and theoretical physics and chemistry into a new domain, particularly with respect to relatively new constructs such as chaos, fractals, and self-organized criticality. However, the notions of evolutionary geomorphology show that threads of inquiry within geomorphology also lead to the consideration of nonlinear complexity in earth surface systems, independently of ideas transferred from other fields. Most of the fundamental implications of nonlinear and complexity science as they apply to earth surface processes and landforms are entirely consistent with existing and well-known (though certainly not necessarily universally accepted) concepts in geomorphology developed via geographical and geological reasoning (Phillips, 1992).

\section{Nonlinearity in geomorphic systems}

Notwithstanding the comments above, nonlinear dynamics and complexity have been widely discussed in geography, geology, and geomorphology with an emphasis on abstractions of theory rather than concrete aspects of surface forms and processes, and on imported rather than home-grown methods and terminology. As a consequence several widelyheld (mis)perceptions exist in the earth science community 
about complex nonlinear dynamics. One is that this type of complexity, readily generated by equation systems, simulation models, and controlled experiments, has not been convincingly demonstrated in real-world earth surface processes and landforms. Another is that some forms of nonlinear complexity, such as deterministic chaos, imply hopelessly innate complexity and an inability to predict. Earth scientists are also often put off by claims on behalf of some strains of nonlinear theory (for example self-organized criticality) that they represent meta-explanations for nature.

These perceptions, while pervasive, are inaccurate. Nonlinear complexity is not necessarily pathological, and may enhance some modes of understanding and predictability. Most scientists working in nonlinear dynamics do not make claims of meta-explanation. Complex nonlinear dynamics are not (merely) an artifact of models, equations, and experiments, but have been observed and documented in many geomorphic phenomena and are not rare or isolated phenomena. These points have been addressed more fully elsewhere (Phillips, 2003a), along with arguments that the identification of and engagement with nonlinear dynamics in earth surface systems has profound implications for prediction, explanation, and application.

Geomorphology is dominantly (and appropriately) an empirical discipline where ground truth is paramount and "field relations are the final court of appeal" (Bretz, 1962). Thus, while acknowledging the critical roles of theory, modeling, and experimentation, geomorphologists ultimately find work with a field component most convincing, and understanding nonlinear dynamics (and applying the lessons therefrom to practical problems) requires linking complex system behaviors to histories, relationships, and phenomenologies in real landscapes. This further implies a need to problematize based on principles and conceptual frameworks of the earth and environmental sciences, as opposed to those of the mathematical and laboratory sciences.

\subsection{Causes of nonlinearity}

A system is nonlinear if the outputs (or responses or outcomes) are not proportional to the inputs (or stimuli, changes, or disturbances) across the entire range of the latter. Nonlinearity creates possibilities for complex behavior not possible in linear systems. However, nonlinear systems may be simple and predictable, and complexity may have causal roots other than nonlinearity. Geomorphic systems are overwhelmingly nonlinear, owing to a number of general phenomena summarized in Table 1 and discussed in detail by Phillips (2003a). These phenomena are mostly common to ecosystems and to earth surface systems in general (Phillips, 2004).

Threholds are of particular significance in geomorphology, as discussed by Chappell (1983), Schumm $(1979,1991)$, Coates and Vitek (1980) and any geomorphology textbook published in the last 20 years. In simple terms a threshold is the point at which a system's behavior changes. Geomorphic thresholds may be either intrinsic, and associated with the inherent structure or dynamics of the geomorphic system, or extrinsic, associated with external factors such as climate, tectonics, and base level. Most commonly geomorphic thresholds are of two general types: the ratio of force or power (or a surrogate thereof) to resistance, or the relative rates of linked processes. Examples of force:resistance thresholds include shear strength vs. shear stress in slope stability, and critical stream power or wind velocity in sediment transport and deposition. Examples of linked process thresholds include relative rates of regolith formation and erosion, and glacial accumulation vs. ablation.

Recently it has been argued that some nonlinear systems evolve to a "critical" state, generally characterized by proximity to a threshold. Schumm (1979) argued that due to the predominance of thresholds, landforms typically evolve to a condition of incipient instability. Schumm's work thus anticipates recent studies of self-organized criticality, but arrives at similar basic conclusions based on geological reasoning.

Other key sources of nonlinearity in geomorphology include storage effects, saturation and depletion relationships, self-reinforcing positive feedbacks, self-limiting negative feedbacks, "competitive" relationships (for example between soil erosion and vegetation cover), multiple modes of adjustment, self-organization, and hysteresis. These are summarized in Table 1, and geomorphic examples given in Phillips (2003a). These general sources of nonlinearity are overlapping and interrelated, and despite the generality of the list, it is undoubtedly not exhaustive.

Self-organization deserves further comment, as the term has various and often conflicting definitions, some of which are unrelated to complex nonlinear dynamics, and some of which are subsumed in the categories above (Phillips, 1999b). Some forms, such as self-organized criticality, involve nonlinearities as systems evolve toward critical states (e.g. Dearing and Zolitschka, 1999; Gomez et al., 2002). Others, such as dynamically unstable selforganization (Phillips, 1999b) are an outcome rather than a cause of nonlinearity. In the most general sense selforganization refers to the formation of patterns attributable to the internal dynamics of a geomorphic system, independently of external controls or inputs. Because this may offset or intensify the effects of external forcings and boundary conditions, self-organization may be a source of nonlinearity in a system.

\subsection{Implications of nonlinearity}

Nonlinearity implies landforms and landscapes are likely to vary in their sensitivity to environmental change. Systems near a threshold, approaching saturation, or characterized by strong positive positive or overcompensating negative feedbacks, for example, are much more sensitive to a given disturbance than would otherwise be the case. Landscape sensi- 
Table 1. Sources of nonlinearity in geomorphic systems (adapted from Phillips 2003a).

\begin{tabular}{|c|c|c|}
\hline sworn w & 领/S/ & 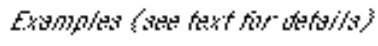 \\
\hline Thresholds & $\begin{array}{l}\text { Where thresholds exist, } \\
\text { outputs or responses by } \\
\text { definition cannot be } \\
\text { proportional to inputs or } \\
\text { stimuli across the entire range } \\
\text { of the inputs }\end{array}$ & $\begin{array}{l}\text { Force vs. resistance; relative } \\
\text { rates of linked processes }\end{array}$ \\
\hline Storage effects & $\begin{array}{l}\text { Addition or removal of mass } \\
\text { from storage creates lags and } \\
\text { discontinuities in mass } \\
\text { balances and input-output } \\
\text { relationships }\end{array}$ & $\begin{array}{l}\text { Sediment transport, storage, } \\
\text { and deposition }\end{array}$ \\
\hline Saturation and Depletion & $\begin{array}{l}\text { Effects of a unit change in an } \\
\text { input or forcing varies with } \\
\text { respect to some optimum }\end{array}$ & $\begin{array}{l}\text { Effects of moisture availability } \\
\text { on weathering rates; effect of } \\
\text { soil/regolith thickness on } \\
\text { bedrock weathering }\end{array}$ \\
\hline $\begin{array}{l}\text { Self-reinforcing, positive } \\
\text { feedback }\end{array}$ & $\begin{array}{l}\text { Changes or disturbances } \\
\text { promote their own growth and } \\
\text { development independently of } \\
\text { external forcings }\end{array}$ & $\begin{array}{l}\text { Growth of solutional } \\
\text { depressions and nivation } \\
\text { hollows; enhancement of } \\
\text { variations in weathering/ } \\
\text { erosion resistance; } \\
\text { preferential flow' phenomena }\end{array}$ \\
\hline Self-limiting processes & $\begin{array}{l}\text { Developmental pathways are } \\
\text { limited by internal factors } \\
\text { independently of external } \\
\text { forcings }\end{array}$ & $\begin{array}{l}\text { Weathering limited by } \\
\text { depletion of weatherable } \\
\text { minerals; diffusional slope } \\
\text { degradation; floodplain vertical } \\
\text { accretion }\end{array}$ \\
\hline $\begin{array}{l}\text { Opposing or competitive } \\
\text { interactions or feedbacks }\end{array}$ & $\begin{array}{l}\text { Opposing interactions or } \\
\text { competitive feedbacks may } \\
\text { cause systems to tip or switch } \\
\text { abruptly }\end{array}$ & $\begin{array}{l}\text { Vegetation-erosion } \\
\text { interactions; indirect } \\
\text { geomorphic effects of ecological } \\
\text { competition }\end{array}$ \\
\hline Multiple modes of adjustment & $\begin{array}{l}\text { Multiple possible } \\
\text { configurations in response to a } \\
\text { single forcing or set of } \\
\text { boundarv conditions }\end{array}$ & Fluvial hydraulic geometry \\
\hline Self-organization & $\begin{array}{l}\text { May involve complex } \\
\text { adaptations independent of } \\
\text { external forcings }\end{array}$ & $\begin{array}{l}\text { Flow-bedform interactions; } \\
\text { periglacial patterned ground; } \\
\text { channel networks }\end{array}$ \\
\hline Hysteresis & $\begin{array}{l}\text { A dependent variable may have } \\
\text { two or more values associated } \\
\text { with a single value of an } \\
\text { independent variable }\end{array}$ & $\begin{array}{l}\text { Discharge vs. sediment } \\
\text { transport relationships; river } \\
\text { channel changes; solute } \\
\text { concentrations }\end{array}$ \\
\hline
\end{tabular}

tivity in this sense is discussed at length by Brunsden (1980), Begin and Schumm (1984), Downs and Gregory (1995), and Thomas (2001).

Nonlinearity admits the possibility of dynamical instability and chaos (equivalent in the case of nonlinear dynamical systems). While the significance of this in geomorphology is contested, the evidence that geomorphic systems can be, and often are, chaotic is now overwhelming, even when work based strictly on models is excluded. Several available reviews should suffice to make this point (Baas, 2002; Christofoletti, 1998; Hergarten, 2002; Phillips, 1999a, 2003a, 2005; Sivakumar, 2000, 2004a; Thomas, 2001). The implications are discussed below.

\subsection{Dynamical instability and chaos}

Geomorphic systems are not all, or always, chaotic. Indeed, many appear to have both stable, non-chaotic modes and unstable, chaotic modes (Phillips, 1999a, 2003a, 2005). Implications for long-term landscape evolution are discussed elsewhere (Phillips, 2003b, 2005). Here the focus is on predicting and responding to effects of environmental change on geomorphic processes and forms.

Geomorphic systems are conceptualized as $n$-dimensional systems with components $x_{i}, i=1,2, \ldots \ldots, n$, such that

$$
d x_{i} / d t=f(d \boldsymbol{x} / d t)
$$


where $\boldsymbol{x}$ indicates the vector of all $x_{i}$. Thus the components of the system potentially effect, and are potentially effected by, each other. The system state at time $t$ is given by

$\boldsymbol{x}(t)=\boldsymbol{C} \boldsymbol{x}(o) e^{\lambda t}$

where $\boldsymbol{x}(o)$ is the initial state (at the onset of landscape evolution or at the time of a change or disturbance) and $C$ is a vector constant related to the initial conditions. The $\lambda$ are the $n$ Lyapunov exponents of the system (equivalent to the real parts of the complex eigenvalues of a Jacobian interaction matrix of the system), where $\lambda_{1}>\lambda_{2}>\ldots \lambda_{n}$.

If randomly selected pairs of locations in a landscape are compared in terms of some indicator of system state (elevation or regolith thickness, for example), the mean difference or separation at time $t$ is given by

$\delta(t)=k e_{1^{t}}^{\lambda}$

where the constant $k$ normalizes the initial separation and $\lambda_{1}$ is the largest Lyapunov exponent.

Stable, nonchaotic geomorphic systems have all $\lambda_{0}$, while any positive exponent $\left(\lambda_{1}>0\right)$ indicates instability and chaos. Methods for detecting and analyzing chaos in geomorphic and hydrologic systems are discussed elsewhere (Phillips, 1999a; Sivakumar, 2000, 2004a). The key point here is the (finite) exponential divergence that occurs in unstable, chaotic geomorphic systems.

Because the effects of minuscule initial variations and small disturbances are exaggerated over time, the implications for geomorphic response to environmental change are that

1. Small changes may produce disproprotionately large results.

2. Short disturbances may have dispoportionately longlived effects.

3. Evidence of landform change may not reflect proportionally large environmental changes or events.

In the absence of perfect isotropy, initial conditions vary locally. This sensitivity to initial conditions leads to a fourth implication:

4. Geomorphic systems may have multiple response trajectories or modes of adjustment to changes.

For instance, the nonlinear dynamical systems models of Thornes (1985) and Kirkby (1995) indicate that the relationship between vegetation and soil erosion in semiarid environments is unstable. When disturbed, the system will "tip" to either a maximum vegetation/no erosion or maximum erosion/no vegetation state. These predictions have been validated by subsequent field studies (Abrahams et al., 1995; Puigdefabregas and Sanchez, 1996). Stratigraphic, morphological or other evidence of erosional episodes or vegetation changes therefore may not imply a major change in climate, land use, or other forcings, but the "tipping" of the unstable system in response to a small, short-term perturbation such as a storm, a fire, or the grazing of a cattle herd.

Other examples include Dearing and Zolitschka (1999), who addressed the implications of nonlinear complexities in interpreting lake sediment archives, demonstrating how complex internal dynamics rather than external forcings account for some observations in the sediment record. Gaffin and Maasch (1991) showed that multiple equilibria associated with nonlinear feedbacks can result in large coastal onlap shifts associated not with accordingly large sea level change, but rather arising from small perturbations. The behavior of glacial feeder systems has been reconstructed from steepfaced glaciodeltaic progradational successions, but Richards and others (2000) showed that such glacier-fed successions in Ireland and Scandinavia have evidence of complex nonlinear dynamics, leading to sedimentation patterns that reflect internal interactions involving delta front steepness and sediment texture, rather than external forcings.

Predicting or interpreting geomorphic responses to climate change thus requires that chaotic or potentially chaotic systems be identified. More specifically, as many systems have both stable and unstable modes, and as both stability and instability are emergent behaviors which appear and disappear as temporal and spatial scales are changes, the scales or circumstances under which chaos and instability are relevant need to be determined. Chaos detection methods are discussed in a separate paper (Phillips, 2006).

\section{Prediction}

Due to (among other things) nonlinear complexity, predicting the response of landforms and surface processes to climate change cannot rely uncritically on "equilibrium" frameworks based on the notion of a new steady-state configuration. Neither can it be safely assumed that responses will be quantitatively or even qualitatively similar to those in the historical record. Where does this leave us?

One approach is probabilistic. Stochastic forecasting methods work equally well whether the phenomenon is truly random or merely apparently so (as in a chaotic sequence). Probabilistic methods can be improved on in a chaotic system, as the pseudo-random behavior occurs within well-defined boundaries. A possible analog to some problems of geomorphic predictability is the field of demographics, where individual human behavior is inherently unpredictable, but characteristic aggregate behaviors can be probabilistically predicted.

A second possibility is to exploit chaotic dynamics. Chaos may preclude deterministic long-term prediction, but does not preclude iterative, short-term predictions. A number of studies in geomorphology, sedimentology, and hydrology have shown that where chaos exists nonlinear prediction models give better results than either traditional deter- 
ministic or stochastic models (Barton et al., 2003; Jaffe and Rubin, 1996; Lall et al., 1996; Porporato and Ridolfi, 2001; Sangoyami et al., 1996). Sometimes the unstable growth of small perturbations, but with finite and well-defined limits and aggregate statistical regularity, is reflected in a syndrome of chaotic instability at one scale resolved into orderly, even regular patterns at a broader scale. Studies based on this approach have led to improved models of fluvial, coastal, and aeolian bedforms (e.g., Nelson, 1990; Rey et al., 1995; Rubin, 1992; Werner, 1995).

A third approach to prediction exploits the emergent properties of chaos. A deterministically chaotic system, by definition, has some underlying deterministic dynamics, which may be (though are not necessarily) quite simple. Likewise, at broader scales the complex irregularities are bounded, and exhibit some degree of irregularity. Turbulent flows are a canonical example (Escultura, 2001; Tsinober, 1998), where the basic underlying physics are well known and deterministic predictions are straightforward where particle interaction is insignificant. The complex interactions of more than a few particles, however, is chaotic, and the location and velocity of any given particle is unpredictable in any deterministic sense more than a few instants into the future. At still broader scales, however, the aggregate fluid flows are quite adequately predicted from gravitational and pressure gradients. In some cases it may be possible to restrict or expand spatial or temporal scales to get into a non-chaotic mode.

In meteorology, despite vast improvements in deterministic modeling and atmospheric physics and chemistry, the backbone of forecasting is still synoptic meteorology and climatology-the study of weather maps, though now largely automated and embedded in numerical models. By examining situations in spatial and temporal context, behavioral typologies are developed. The atmospheric equations of motion are a classic example of chaos, but with general physical "global" laws and "local" synoptic observations constraining each other, reasonable predictions are possible. This suggests a useful analog for geomorphology, where avowedly synoptic, event-based, or situationally-constrained forecasts have been shown to be effective in several recent cases (Knighton and Nanson, 2001; Knox, 2000; Miller et al., 2003; Slattery et al., 2006).

\section{Geography and history}

The implications of instability and chaos in predicting geomorphic responses could be summed up as: Geography matters, and history matters. Geography matters because local variations and disturbances result in increasing divergence over time. History matters because geomorphic systems "remember" initial variations and perturbations.

Because geography and history matter, factors and controls specific to place and time (local factors) are irreducibly significant - a source of frustration to many geomorpholo- gists, who like other scientists strive for explanation and prediction based on "global" laws (or principles or generalizations) which are independent of time and place.

Several recent developments in the earth and environmental sciences support the emerging view that historical and spatial contingencies are ubiquitous and must be engaged on their own terms - that is, the contingencies cannot be subsumed under global laws by simply collecting more and better data or constructing more involved models. These developments include a shift away from a search for global generaliizations within spatial data to efforts to explain spatial variability by explicitly incorporating local factors (socalled local forms of spatial analysis). This shift is most evident in quantitative geography (Fotheringham and Brunsdon, 1999), and successful applications in geomorphology include Atkinson et al. (2003) and Nelson (2001). Landscape ecology and soil geography have also focused on explaining spatial variability rather than extracting global laws, with the dominant conceptual frameworks based on the search for applicable process laws within local and regional contexts (Christakos, 2002; Goovaerts, 1999; Haines-Young and Chopping, 1996; Ibanez et al., 1995; Walsh et al., 1998).

Studies of effects of high-magnitude, low-frequency events further underscores the inescapable elements of historical and geographical contingency in geomorphology. Impacts of floods, hurricanes, and other large events may be influenced or controlled by event timing, sequence, and initial conditions in addition to (or rather than) event magnitude and force-resistance relationships governed by generallyapplicable laws. Because timing, sequence, and initial conditions are inherently contingent, effects of such events cannot be (entirely) addressed via global laws. Examples include Carling and Beven (1989), Lecce et al. (2004), Magilligan (1992), Magilligan et al. (1998), Miller et al. (2003); Phillips (1999c); and Pickup (1991).

The critical role of place- and time-based explanation is also indicated by a cumulative and repeated inability to extract generalizations. For example, Schumm et al.'s (2000) book on tectonics and alluvial rivers relies heavily on four case studies, but generalizations are still hard to come by: "Because the four rivers are subjected to different types of active tectonism and each river is different, the only firm conclusion that can be reached is that deformation causes river variability" (p. 151). Similarly, even in a relatively restricted geographical context no generalizations about downstream geomorphic effects of dams on large rivers could be discerned (Friedman et al., 1998). A multi-investigator, multinational effort to link landslides to climate change in Europe was no more successful in producing generalizations: “...the complexity of the relationship between climate and landsliding seems to make it not feasible to establish 'universal laws' all over Europe" (Dikau and Schott, 1999:1).

In geomorphology and the earth sciences more broadly, the undeniable role of history has repeatedly defeated efforts to understand landscape entirely on the basis of reduction- 
ist global laws, and concern over global change has rejuvenated palaeoenvironmental reconstructions. The recognition that landscape evolution has irreducible elements of contingency and path-dependency leads to acknowledgement that in many cases geomorphology calls for an approach to science fundamentally different from that of the reductionist laboratory science ideal (e.g., Baker, 1996; Bishop, 1998; Harrison, 1999; Spedding, 1997). Several recent studies explicitly address the necessity of dealing with historical contingency in specific field problems (Bishop, 1998; Brierly and Fryirs, 2005; Fryirs, 2002; Lane and Richards, 1997; Sauchyn, 2001; Vandenbergehe, 2002).

Contingency can arise from a number of different phenomena, and would be an issue even without complex nonlinear dynamics. However, the fact that geomorphic systems in many cases are dynamically unstable indicates that initial variations matter, local disturbances matter, and history matters. This indicates that the components of a geomorphic system as described in Eq. (1) can be represented as

$\boldsymbol{x}=x_{g}+x_{l}$

where $x_{g}$ represents the components governed or represented by laws, regularities, or relationships which are widely applicable and not place- or time-specific. Components $x_{l}$ are associated with local, contingent factors.

Geomorphic problems can be defined so that that only global factors are relevant, or so that local factors have negligible influence. The response of landforms and landscapes to climate or other changes, however, is not ultimately concerned with changes in the stability of a simplified or idealized slope, or the erosion of a modelled field. Eventually, the fate of specific landforms and landscapes must be addressed, involving both $x_{g}$ and $x_{l}$.

Returning to the notions of evolutionary geomorphology as the trajectory of system states through time, the state of a geomorphic system (combining Eqs. 2 and 3) is

$x(t)=f\left(\boldsymbol{C}, x_{g}(o), x_{l}(o), \lambda\right)$

A beach, for instance, is determined partly by global laws and general relationships pertaining to the physics of wave generation, propagation, shoaling, and breaking; sediment entrainment and transport; wave-nearshore-beach interactions; etc. The state of the beach (defined, for example, on the basis of its morphology or erosion/accretion status) is also determined on the basis of a number of local, contingent factors such as recent storm, wind and wave history, underlying geologic controls, sea level history, vegetation, proximity to sediment sources and sinks, and human (or other animal) effects.

With $i=1,2, \ldots, n$ general or global controls $x_{g, i}$, and $j=1$, $2, \ldots, m$ local or contingent controls $x_{l, j}$, the probability of a specific state $p(S)$ is a function of the joint probabilities:

$$
\begin{aligned}
& n \quad m \\
& p(S)=\Pi p\left(x_{g, i}\right) \Pi p\left(x_{l, j}\right),
\end{aligned}
$$

where probabilities $p\left(G_{i}\right) p\left(L_{j}\right) \leq 1$. The $p\left(x_{g, i}\right)$ may approach unity in some cases-this is certainly the ideal, though in practice even universal laws are conditioned by uncertainty associated with parameterization and the form of the relevant law. However, $p\left(x_{l, j}\right)<1$, and often $<<1$. Accordingly, $p(S)<<1$, assuring (alas) at least some elements of uniqueness in every landscape.

Equation (5) shows that the key to increasing generality of landscape decriptions and analyses comes from reducing the number of components, variables, or controls considered, as including more $x_{g, i}$ or $x_{l, j}$ can only reduce $p(S)$. The more variables and parameters included, or the more processes modelled, the more singular the outcome.

\section{The way forward}

This analysis should not discourage the search for generalizations, or be interpreted as advocating a purely idiographic approach. It should be clear that both global and local factors are critical in geomorphic systems, and that approaches exclusively based on one or the other, while perhaps successful in particular problems or applications, cannot ultimately explain landscape evolution and response.

In general, the way forward involves dealing with the mutual constraints of local and global factors on each other. Understanding changes in karst processes and landforms in response to climate change, for example, will require addressing the particular combination of lithologic, structural, topographic, and biotic (at least) controls in an area, and many potential specific outcomes are possible. However, general principles of karst geomorphology should allow one to rule out some possibilities, and to further identify lower- and higher-probability responses. Conversely, general principles of fluvial reponse to sea-level changes can inform predictions of responses to climate change, but river-specific predictions must be made in the context of the particular geologic and hydrologic controls and recent geomorphic history of the river.

More specifically, we may seek generalizations in pareddown, more generalized models-recognizing that the more pared-down, the more general- and then embed within these specific field problems.

Hergarten (2002) and Werner (1999) have argued that the fundamental qualitative behavior of geomorphic systems is more important than the quantitative details. This is a persuasive argument in an applied context, as questions such as whether or not gully erosion may be initiated on rangeland as a consequence of environmental change are far more important than predicted rates of soil removal or gully incision. The types of analyses recommended and illustrated, while rigorous and mathematical, are essentially phenomenological and qualitative or semi-quantitative. This approach has been successful in modeling and explaining (among other things) landslides, aeolian dunes, soil erosion, beaches, glaciers, channel networks, and periglacial patterned ground 


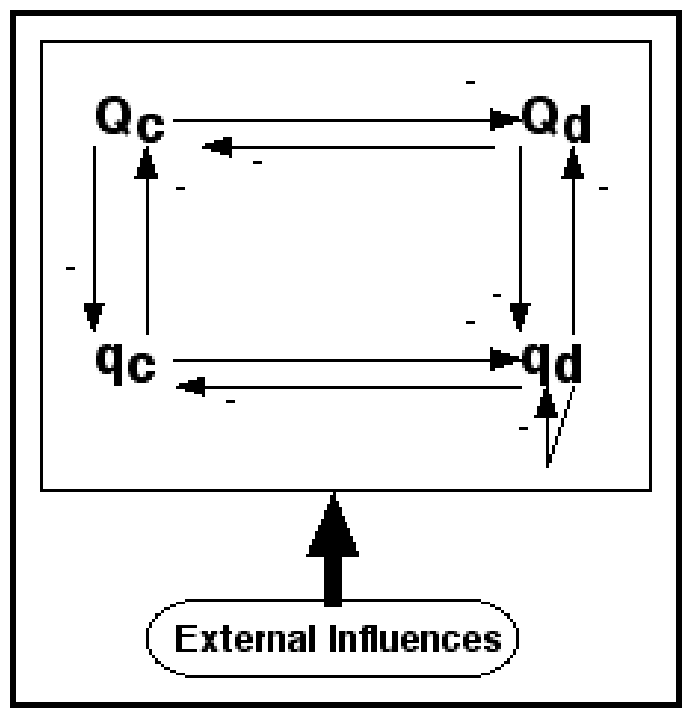

Fig. 1. Flow partitioning model for fluviokarst landscapes in central Kentucky, after Phillips and Walls (2004). The model is based on a mass balance partition of a unit of effective precipitation among surface $(Q)$ and subsurface $(q)$ flow, in each case allocated into concentrated (subscript $c$ ) or diffuse $(d)$ flow. Included links are based on field observations in the study area.

(Hergarten, 2002; Werner and Fink, 1994; Werner, 1995; Favis-Mortlock, 1998; Masselink, 1999; Bahr and Meier, 2000; De Boer, 2001).

Methodologically distinct but conceptually similar is qualitative modeling based on the set of positive, negative, or negligible interrelationships among the key components of a geomorphic system. Originally conceived (or at least perceived) as an expedient in the absence of data or knowledge necessary to fully specify the quantitative relationships, a number of authors have pointed out that qualitative models actually increase the generality of the results (Escultura, 2001; Harrison, 1999; Phillips, 1992, 1999a; Phillips and Walls, 2004; Slingerland, 1981; Trofimov and Moskovkin, 1984). While the quantitative aspects of many processes and relationships are highly variable, the qualitative features may be universal (for example fully developed turbulence; Escultura, 2001; Tsinober, 1998; weathering and erosion; Phillips, 2005). Specific quantitative relationships between vegetation cover and erosion, for instance, are strongly variable in space and time, while the qualitative link (more vegetation cover = greater resistance) applies always and everywhere. Qualitative stability models have been particularly successful in ecology (see reviews by Logofet, 1993; Pahl-Wostl, 1995), but there are also several examples of fruitful applications in geomorphology (see reviews by Phillips, 1999a, 2005).

Hydrology faces closely related problems of contingency (Beven, 2000). The dominant processes concept (DPC) is a recognition that there are difficulties in trying to model all potentially relevant processes. These difficulties, along with

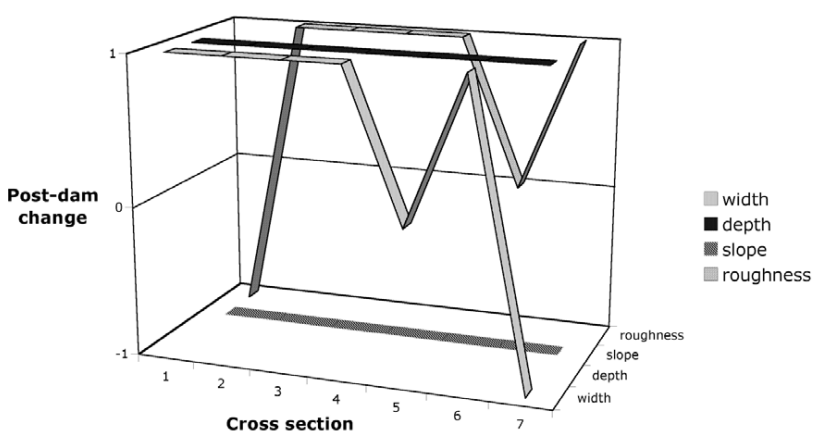

Fig. 2. General pattern of increases (1), decreases $(-1)$, or negligible change (0) at seven cross-sections in a $55 \mathrm{~km}$ reach downstream of Livingston Dam on the Trinity River, Texas, following dam construction.

field observations that often only a few processes dominate hydrological responses in any watershed, and the cumulative experience of modellers, which suggests that simple models with a few dominant factors can capture the essential features of hydrologic response (Sivakumar, 2004b). Hydrological analysis should therefore be based on simpler models and fewer processes, but with the included processes tied to local conditions in individual watersheds.

\subsection{Examples}

Below, I will highlight two attempts by myself and coworkers to implement the general approach described above. This is in the spirit of practicing what one preaches; I am not suggesting these as exemplars. For the latter, at least in an applied framework, I recommend Brierly and Fryirs (2005) recent book on geomorphology and river management.

Michael Walls and I (Phillips and Walls, 2004), used an approach similar to the DPC in our study of divergent evolution of fluviokarst landscapes in central Kentucky. A qualitative model of flow partitioning (Fig. 1) between surface and subsurface, and between concentrated and diffuse, flow was used to explain the tendency of the most eroded portions of the study area to diverge into either strongly karstified zones with few or no channels, or fluvially-dissected zones with few solutional landforms. The qualitative model is very general in that it is based on a universal mass balance principle, whereby all effective precipitation (precipitation minus evapotranspiration) must flow or be stored either at the surface or subsurface, and in either case is either concentrated or diffuse. Even as applied to the study area this partitioning does not depend on specific, necessarily local, parameterizations.

Conversely, some of the links in the model are not universal, and the sign of those links in our model was based on conditions and field observations within the study area. The model is entirely "competitive" in the sense that once moisture is in one of the four states it remains there. While clearly true on an instantaneous basis (water cannot be in two 
places simultaneously), in some systems and situations transfers such as subsurface to surface return flow or exfiltration or channelization of diffuse flow are important. This particular system construction is based on our study area-specific observations that the initial disposition of runoff is the critical factor for landform development (Phillips et al., 2004; Phillips and Walls, 2004). Results are not applicable to all fluviokarst landscapes, but are potentially relevant to those where the links in the flow partitioning model are the same as in the inner Bluegrass region of Kentucky.

The second example involves downstream geomorphic effects of a dam, viewed as an opportunistic experiment to assess what happens if (in this case) sediment load is drastically reduced without significant change in the discharge regime. The interrelationships between width, depth, velocity, roughness, and slope at a cross-section are dynamically unstable, indicating multiple modes of adjustment, complex responses, and an inability to predict even qualitative responses without specific information at each cross-section. Thus the response of the Trinity River channel (southeast Texas) is characterized by qualitatively different combinations of increases, decreases and relative constancy of channel width, depth, slope, and roughness following construction of Livingston Dam (Phillips et al., 2005).

The qualitative system model of the interaction of the hydraulic variables, the instability of these interrelationships, and the implications thereof, are universal and applicable to any fluvial system. However, the range of possible responses is constrained not only by fundamental flow resistance hydraulics, but also by the systematic qualitative relationships between discharge, slope, sediment load, and grain size that underpin essentially all hydraulic geometry models (Phillips et al., 2005). These in turn depend on site-specific and historically contingent factors such as substrate and bank material, geologic setting and history, vegetation, flood history, and many other factors. For example, adjustments of depth and slope via incision in our study reach are limited at present because the Trinity River has already incised to resistant bedrock.

In this example, the applicable global laws constrain the possible responses, guide the interpretation of observed responses, and allow for some generalization to other cases. However, these laws cannot (by themselves) explain changes at specific cross-sections, and allow for multiple outcomes. The specific place- and time-specific details of the study area can, in conjunction with the laws, explain observations and allow predictions (Phillips et al., 2005). However, by themselves these local details have little or no relevance beyond the study area. The combination of the two, as mandated by an evolutionary approach to geomorphology, as necessary to explain the system under study.

\section{Conclusions}

Thresholds, nonlinearity, and complex dynamics in geomorphic systems suggest that we are quite limited in discerning universal laws applicable to predicting geomorphic response to environmental change. Rather, the suggestion is to refocus on a search for lessons - typologies, patterns, and synoptic situations we can learn from. In that spirit, the major proposed lessons of this paper can be summarized as follows:

- Geomorphic systems are typically nonlinear, owing largely to their threshold-dominated nature (but due to other factors as well).

- Nonlinear geomorphic systems are capable of complex behaviors not possible in linear systems, including dynamical instability and deterministic chaos.

- Dynamical instability and chaos are common in geomorphic systems, indicating that small, short-lived changes may produce disproportionately large and longlived results; that evidence of geomorphic change may not reflect proportionally large external forcings; and that geomorphic systems may have multiple potential response trajectories or modes of adjustment to change.

- Instability and chaos do not preclude predictability, but do modify the context of predictability. The presence of chaotic dynamics inhibits or excludes some forms of predicability and prediction techniques, but does not preclude, and enables, others.

- Geography matters.

- History matters.

- While the geographical and historical contingency indicated above would occur independently of complex nonlinear dynamics, instability and chaos dictate that such contingency is important.

- Geomorphic systems are thus governed by a combination of "global" laws, generalizations and relationships that are largely (if not wholly) independent of time and place, and "local" place and/or time-contingent factors.

- The more components, variables or processes included in the representation of any geomorphic system, the more singular the results or description are. Generalization is enhanced by reducing rather than increasing the number of factors considered.

- Prediction of geomorphic responses calls for a recursive approach whereby global laws and local contingencies are used to constrain each other. More specifically, I advocate a methodology whereby local details (be they process mechanical, historical, or both) are embedded within simple but more highly general phenomenological models. There are examples of successful applications of the advocated approach. 
Landscapes and landforms change over time, and in response to changes in climate and other external forcings. It cannot be assumed that geomorphic systems progress along any particular pathway, whether that pathway leads to a steady-state form, a peneplain, or any other predordained endpoint. Geomorphic systems are evolutionary in the sense of being path dependent, and historically and geographically contingent. Assessing and predicting geomorphic responses obliges us to engage these contingencies, which often arise from nonlinear complexities. We are obliged, then, to practice evolutionary geomorphology.

Acknowledgements. The invitation from M. Sivapalan, C. Hinz, and G. Hancock to present these ideas at a conference in 2005 was instrumental in leading to the crystallization of thoughts expressed in this paper. Helpful review comments from A. James are greatly appreciated.

Edited by: M. Sivapalan

\section{References}

Abrahams, A. D., Parsons, A. J., and Wainwright, J.: Effects of vegetation change on interrill runoff and erosion, Walnut Gulch, Arizona, in: Biogeomorphology, Terrestrial and Freshwater Systems, Proceedings of the 26th Binghamton Geomorphology Symposium, edited by: Hupp, C. R., Osterkamp, W., and Howard, A., Amsterdam, Elsevier, 37-48, 1995.

Atkinson, P. M., German, S. E., Sear, D. A.,and Clark, M. J.: Exploring the relations between riverbank erosion and geomorphological controls using geographically weighted logistic regression, Geogr. Anal., 35, 58-83, 2003.

Baas, A. C. W.: Chaos, fractals, and self-organization in coastal geomorphology: simulating dune landscapes in vegetated environments, Geomorph., 48, 309-328, 2002.

Bahr, D. B. and Meier, M. F: Snow patch and glacier size distributions, Water Resour. Res., 36, 495-501, 2000.

Baker, V. R.: Hypotheses and geomorphological reasoning, in: The Scientific Nature of Geomorphology, edited by: Rhoads, B. L. and Thorn, C. E., Wiley, New York, 57-86, 1996.

Barton, C. C., Dismukes, J. S., and Morton, R. A.: Complexity analysis of the change in shoreline position at Duck, North Carolina, in: Coastal Sediments '03, edited by: Davis, R. A., American Society of Civil Engineers, New York, 1-7, 2003.

Begin, Z. B. and Schumm, S. A.: Gradational thresholds and landform singularity: significance for Quaternary studies, Quat. Res., 27, 267-274, 1984.

Beven, K. J.: Uniqueness of place and process representations in hydrological modeling, Hydrol. Earth Syst. Sci., 4, 203-213, 2000, http://www.hydrol-earth-syst-sci.net/4/203/2000/.

Bishop, P.: Griffith Taylor and the southeast Australia highlands: issues of data sources and testability in interpretations of longterm drainage history and landscape evolution, Austral. Geog. 29, 7-29, 1998.

Bretz, J. H.:. Dynamic equilibrium and the Ozark land forms, Am. J. Sci., 260, 427-438, 1962.

Brierly, G. J. and Fryirs, K. A: Geomorphology and River Management. Blackwell, Oxford, UK, 2005.
Brunsden, D.: Applicable models of long term landform evolution, Z. Geomorph., suppl. 36, 16-26, 1980.

Carling, P. and Beven, K.: The hydrology, sedimentology, and geomorphological implications of floods: an overview, in: Floods: Hydrological, Sedimentological, and Geomorphological Implications, edited by: Beven, K. and Carling, P., Wiley, Chichester, $1-9,1989$.

Chappell, J.: Thresholds and lags in geomorphologic changes, Aust. Geog., 15, 358-366, 1983.

Christakos, G.: On the assimilation of uncertain physical knowledge bases: Bayesian and non-Bayesian techniques, Adv. Water Resour., 25, 1257-1274, 2002.

Christofoletti, A: Noções básica para a compreensáo da establidade e mudanças nos sistemas geograficos. Ciência Geografica 4, 13 19, 1998

Coates, D. R. and Vitek, J. V. (Eds.): Thresholds in Geomorphology, Unwin Hyman, London, 1980.

Dearing, J. A. and Zolitschka, B.: System dynamics and environmental change: an exploratory study of Holocene lake sediments at Holzmaar, Germany, The Holocene, 9, 531-540, 1999.

DeBoer, D. H.: Self-organization in fluvial landscapes: sediment dynamics as an emergent property, Comp. Geosci., 27, 9951003, 2001.

Dikau, R. and Schrott, L.: The temporal stability and activity of landslides in Europe with respect to climate change (TESLEC): main objectives and results, Geomorph., 30, 1-12, 1999.

Escultura, E. E.:. Turbulence: theory, verification, and applications, Nonlinear Anal., 47, 5955-5966, 2001.

Favis-Mortlock, D.:. A self-organizing dynamic systems approach to the simulation of rill initiation and development on hillslopes, Comp. Geosci., 24, 353-372,1998.

Fotheringham, A. S. and Brunsdon, C.: Local forms of spatial analysis, Geogr. Anal., 31, 340-358, 1999.

Friedman, J. M., Osterkamp, W. R., Scott, M. L., and Auble, G. T.: Downstream effects of dams on channel geometry and bottomland vegetation: regional differences in the Great Plains, Wetlands, 18, 619-633, 1998.

Fryirs, K.: Antecedent landscape controls on river character, behavior, and evolution at the base of the escarpment in Bega catchment, New South Wales, Australia, Z. Geomorph., 46, 475-504, 2002.

Gaffin, S. R. and Maasch, K. A.: Anomalous cyclicity in climate and stratigraphy and modeling nonlinear oscillations, J. Geophys. Res., 96B, 6701-6711, 1991.

Gomez, B., Page, M. J., Bak, P., and Trustrum, N. A.: Selforganized criticality in layered lactustrine sediments formed by landsliding, Geol., 30, 519-522, 2002.

Goovaerts, P.: Geostatistics in soil science: state-of-the-art and perspectives, Geoderma, 89, 1-45,1999.

Haines-Young, R. and Chopping, M.: Quantifying landscape structure: a review of landscape indices and their application to forested landscapes, Prog. Phys. Geog., 20, 418-445, 1996.

Harrison, S.: The problem with landscape, Geogr., 84, 355-363, 1999.

Hergarten, S.: Self-organized Criticality in Earth Systems, Springer, Berlin, 2002.

Huggett, R. J.: Geoecology: An Evolutionary Approach, Routledge, London, 1995.

Huggett, R. J.: Environmental Change. The Evolving Ecosphere, 
Routledge, London, 1997.

Ibanez, J. J., De-Alba, S., Bermudez, F.-F., and Garcia-Alvarez, A.: Pedodiversity: concepts and measures, Catena 24, 215-232, 1995.

Jaffe, B. E. and Rubin, D. M.: Using nonlinear forecasting to learn the magnitude and phasing of time-varying sediment suspension in the surf zone, J. Geophys. Res., 101C, 14 283-14 296, 1992.

Johnson, D. L., Keller, E. A., and Rockwell, T. K.: Dynamic pedogenesis: new views on some key soil concepts, and a model for interpreting Quaternary soils, Quat. Res. 33, 306-319, 1990.

Johnson, D. L. and Watson-Stegner, D.: Evolution model of pedogenesis, Soil Sci., 143, 349-366, 1987.

Kirkby, M. J.: Modelling the links between vegetation and landforms, in: Biogeomorphology, Terrestrial, and Aquatic Systems, edited by: Hupp, C. L., Osterkamp, W. R., and Howard, A., Elsevier, Amsterdam, 319-335, 1995.

Knighton, A. D. and Nanson, G. C.: An event-based approach to the hydrology of arid zone rivers in the channel country of Australia, J. Hydrol., 254, 102-123, 2001.

Knox, J. C.: Sensitivity of modern and Holocene floods to climate change, Quat. Sci. Rev. 19, 439-451, 2000.

Lall, U., Sangoyami, T., and Abarbanel, H. D. I.: Nonlinear dynamics of the Great Salt Lake: nonparametric short-term forecasting, Water Resour. Res., 32, 975-985, 1996.

Lane, S. N. and Richards, K. S.: Linking river channel form and process: time, space, and causality revisited, Earth Surf. Proc. Landf., 22, 249-260, 1997.

Lecce, S. A., Pease, P. P., Gares, P. A., and Rigsby, C. A.: Floodplain sedimentation during an extreme flood: the 1999 flood on the Tar River, eastern North Carolina, Phys. Geog., 25, 334-346, 2004.

Logofet, D. O.: Matrices and Graphs: Stability Problems in Mathematical Ecology, CRC Press, Boca Raton, FL, 1993.

Magilligan, F.J.: Thresholds and the spatial variability of flood power during extreme floods, Geomorph., 5, 373-390, 1992.

Magilligan, F. J., Phillips, J. D., Gomez, B., and James, L. A.: Geomorphic and sedimentological controls on the effectiveness of an extreme flood, J. Geol., 106, 87-95, 1998.

Masselink, G.: Alongshore variation in beach cusp morphology in a coastal embayment, Earth Surf. Proc. Landf., 24, 335-347, 1999.

Miller, D., Luce, C., and Benda, L.,: Time, space, and episodicity of physical disturbance in stream, For. Ecol. Manage., 178, 121140, 2003.

Nelson, J. M.:. The initial instability and finite-amplitude stability of alternate bars in straight channels, Earth-Sci. Rev., 29, 97$115,1990$.

Nelson, A.: Analyzing data across geographic scales in Honduras: detecting levels of organization within systems, Agric., Ecosys. Environ., 85, 107-131, 2001.

Ollier, C. D.: Evolutionary geomorphology of Australia and Papua New Guineau, Trans. Inst. Brit. Geog. NS4, 516-539, 1979.

Pahl-Wostl, C.: The Dynamic Nature of Ecosystems, Chaos and Order Entwined, John Wiley, Chichester, UK, 1995.

Phillips, J. D.: Qualitative chaos in geomorphic systems, with an example from wetland response to sea level rise, J. Geol., 100, 365-374, 1992,

Phillips, J. D.: Stability implications of the state factor model of soils as a nonlinear dynamical system, Geoderma, 58, 1-15, 1993.
Phillips, J. D.: Earth Surface Systems, Complexity, Order, and Scale, Basil Blackwell, Oxford, UK, 1999a.

Phillips, J. D.: Divergence, convergence, and self-organization in landscapes, Ann. Assoc. Am. Geog., 89, 466-488, 1999b.

Phillips, J. D.: Event timing and sequence in coastal shoreline erosion: Hurricanes Bertha and Fran and the Neuse estuary, J. Coas. Res., 15, 616-623, 1999c.

Phillips, J. D.: Sources of nonlinear complexity in geomorphic systems, Prog. Phys. Geog., 26, 339-361, 2003a.

Phillips, J. D.: Alluvial storage and the long term stability of sediment yields, Bas. Res., 15, 153-163, 2003b.

Phillips, J. D.: Divergence, sensitivity, and nonequilibrium in ecosystems, Geogr. Anal., 36, 369-383, 2004.

Phillips, J. D.: Weathering, instability, and landscape evolution, Geomorph., 67, 255-272, 2005.

Phillips, J. D.: Deterministic chaos and historical geomorphology: a review and look forward, Geomorph., 76, 109-121, 2006.

Phillips, J. D., Martin, L. L., Nordberg, V. G., and Andrews, W. A.: Divergent evolution in fluviokarst landscapes of central Kentucky, Earth Surf. Proc. Landf., 29, 799-819, 2004.

Phillips, J. D., Slattery, M. C., and Musselman, Z. A.: Channel adjustments of the lower Trinity River, Texas downstream of Livingston Dam, Earth Surf. Proc. Landf., 30, 1419-1439, 2005.

Phillips, J. D. and Walls, M. D.:. Flow partitioning and unstable divergence in fluviokarst evolution in central Kentucky, Nonlin. Processes Geophys., 11, 371-381, 2004, http://www.nonlin-processes-geophys.net/11/371/2004/.

Pickup, G.: Event frequency and landscape stability on the floodplain systems of arid central Australia, Quat. Sci. Rev., 10, 463473, 1991.

Puigdefabregas, J. and Sanchez, G.: Gemorphological implications of vegetation patchiness on semi-arid slopes, in: Advances in Hillslope Processes, edited by: Anderson, M. G. and Brooks, S. M., John Wiley, Chichester, UK, 1027-1060, 1996.

Rey, V., Dames, A. G., and Belzons, M.: On the formation of bars by the action of waves on an erodible bed: A laboratory study, J. Coas. Res., 11, 1180-1194, 1995.

Richards, A., Phipps, P., and Lucas, N.: Possible evidence for underlying non-linear dynamics in steep-faced glaciodeltaic progradational successions, Earth Surf. Proc. Landf., 25, 11811200, 2000.

Rubin, D. M.: Use of forecasting signatures to help distinguish periodicity, randomness, and chaos in ripples and other spatial patterns, Chaos 2, 525-535, 1992.

Sangoyomi, T. B., Lall, U., and Abarbanel, H. D. I.: Nonlinear dynamics of the Great Salt Lake: Dimension estimation, Water Resour. Res., 32, 149-159, 1996.

Sauchyn, D. J.: Modeling the hydroclimatic disturbance of soil landscapes in the southern Canadian plains: the problems of scale and place, Environ. Mon. Assess., 67, 277-291, 2001.

Schumm, S. A.: Geomorphic thresholds: the concept and its applications, Trans. Insti. Brit. Geogr., NS4, 485-515, 1979.

Schumm, S. A.: To Interpret the Earth. Ten Ways to Be Wrong, New York, Cambridge University Press, New York, 1991.

Schumm, S. A., Dumont, J. F., and Holbrook, J. M.: Active Tectonics and Alluvial Rivers, Cambridge University Press, New York, 2000.

Sivakumar, B.: Chaos theory in hydrology: important issues and interpretations, J. Hydrol., 227, 1-20, 2000. 
Sivakumar, B.: Chaos theory in geophysics: past, present, and future, Chaos, Sol. Fract., 19, 441-462, 2004a.

Sivakumar, B.: Dominant processes concept in hydrology: moving forward, Hydrol. Proc., 18, 234-2353, 2004b.

Slattery, M. C., Gares, P. A., and Phillips, J. D.: Multiple modes of runoff generation in a North Carolina coastal plain watershed, Hydrol. Proc., in press, 2006.

Slingerland, R.: Qualitative stability analysis of geologic systems with an example from river hydraulic geometry, Geol., 9, 491493, 1981.

Spedding, N.: On growth and form in geomorphology, Earth Surf. Proc. Land., 22, 261-265, 1997.

Thomas, M. F.: Landscape sensitivity in time and space - an introduction, Catena, 42, 83-98, 2001.

Thornes, J. D.: Evolutionary geomorphology, Geogr., 68, 225-235, 1983.

Thornes, J. B.: The ecology of erosion, Geogr., 70, 222-235, 1985.

Trofimov, A. M. and Moskovkin, V. M.: The dynamic models of geomorphological systems, Z. Geomorph., 28, 77-94, 1984.
Tsinober, A.: Turbulence: beyond phenomenology, in: Chaos, Kinetics, and Nonlinear Dynamics in Fluids and Plasmas, edited by: Benkadda, S. and Zaslavsky, G. M., Springer, Berlin, 85143, 1998.

Vandenberghe, J.: The relation between climate and river processes, landforms, and deposits during the Quaternary, Quat. Internat., 91, 17-23, 2002.

Walsh, S. J., Butler, D. R., and Malanson, G. P.: An overview of scale, pattern, process relationships in geomorphology: a remote sensing perspective, Geomorph., 21, 183-205, 1998.

Werner, B. T.: Eolian dunes: computer simulation and attractor interpretation, Geol., 23, 1107-1110, 1995.

Werner, B. T.: Complexity in natural landform patterns, Science, 284, 102-104, 1999.

Werner, B. T. and Fink, T. M.: Beach cusps as self-organized patterns, Science, 260, 968-971, 1994. 